\title{
İdiyopatik İnflamatuar Medial Meatal Fibrozis: Olgu Sunumu Ve Kısa Literatür Derlemesi
}

\section{Idiopathic Inflammatory Medial Meatal Fibrosis: A Case Report and A Brief Literature Review}

\author{
Gamze ÖZTÜRK YILMAZ ${ }^{1}$, Erdem Atalay ÇETINKAYA ${ }^{1}$, Ömer Tarık SELÇUK ${ }^{1}$, \\ Gökhan YILMAZ ${ }^{1}$, Özer Erdem GÜR ${ }^{1}$
}

${ }^{1}$ Sağlık Bilimleri Üniversitesi Antalya Eğitim ve Araştırma Hastanesi Kulak Burun Boğaz Kliniği, Antalya

\begin{abstract}
Öz
İdiyopatik inflamatuar medial meatal fibrozis (İ̈MMF) işitme azlığ 1 , sık otore ile başvuran, dış kulak yolunda stenoz görülen hastalarda aklımıza gelmesi gereken nadir bir hastalıktır. 65 yaşındaki kadın hasta 15 yıldır sol kulakta işitme azlığı ve tekrarlayan akıntı şikayetiyle başvurdu. Otoskopik bakıda sol dış kulak yolu cildi mediale doğru kalınlaşmış, lümen çapı azalmış, timpan zar kalınlığı artmıştı. Temporal kemik Bilgisayarlı Tomografisinde (BT) sol dış kulak yolu medialinde kalınlaşmış cilt ve timpan zar izleniyordu. Medikal tedavi ile klinik bulgu ve hasta yakınmasında düzelme olmaması üzere cerrahi önerildi. Onlay timpanoplasti uygulandı. Postoperatif takiplerde dış kulak yolu cildinin normal epitelize olduğu ve timpan zarın normal kalınlıkta olduğu görüldü. Bu makalede İIMMF olgusu klinik bulgular, tanı ve cerrahi tedavi süreci ile birlikte güncel literatür eşliğinde sunulmuştur.
\end{abstract}

Anahtar Kelimeler: İdiyopatik, İnflamasyon, Medial Meatal Fibrozis

\section{Giriş}

İIMMF postinflamatuar, travmatik, postoperatif ve neoplastik durumlara bağlı oluşabilir (1). Kronik inflamasyon sonrası İİMMF, dış kulak yolunun nadir görülen, edinilmiş bir atrezisidir. Literatüre bakıldığında, rekürren otitis eksterna ve kronik süpüratif otitis media'nın postinfla- matuar medial meatal fibroziste en önemli predispozan faktörler olduğu görülür (2). Bu pato- lojide dış kulak yolu mediali fibröz doku tarafindan oblitere edilmiştir. Otomikroskopi ile kulak yolunu k1smen tıkayan ağrısız doku tıkacının görülmesi tanıyı kolaylaştırır (3). Fakat nadir görülen bir patoloji olması nedeni ile atrezi yaratmadan tanınması oldukça zordur. $\mathrm{Bu}$ yazıda kliniğimize işitme azlığı ile başvuran, sol dış kulak yolunda stenoz gelişmiş̧ ve rekürren

\begin{tabular}{|c|c|}
\hline & ORCID No \\
\hline Gamze ÖZTÜRK YILMAZ & $0000-0002-9478-7603$ \\
\hline Erdem Atalay ÇETINNKAYA & $0000-0001-6911-5795$ \\
\hline Ömer Tarık SELÇUK & 0000-0002-7364-7599 \\
\hline Gökhan YILMAZ & 0000-0002-1900-3565 \\
\hline Özer Erdem GÜR & 0000-0002-2846-4136 \\
\hline Başvuru Tarihi / Received: & 23.08 .2019 \\
\hline Kabul Tarihi / Accepted : & 26.04 .2020 \\
\hline Adres / Correspondence : & Gamze ÖZTÜRK YILMAZ \\
\hline $\begin{array}{l}\text { Sağlık Bilimleri Üniversite } \\
\text { Hastanesi Kulak Burun Boğaz }\end{array}$ & $\begin{array}{l}\text { si Antalya Eğitim ve Araştırma } \\
\text { z Kliniği, Antalya }\end{array}$ \\
\hline e-posta / e-mail : & : gambu_9199@hotmail.com \\
\hline
\end{tabular}

\begin{abstract}
Idiopathic inflammatory medial meatal fibrosis (IIMMF) is a rare condition that should be kept in mind in patients with hearing loss, frequent otorrhea and stenosis of the external auditory canal. A 65year-old female patient was admitted to our clinic with complaints of recur- rent discharge in the left ear for 15 years. Otoscopic examination revealed that the skin of the left external auditory canal was thickened medially, the lumen diameter was decreased and the thickness of the tympanic membrane was increased. Temporal bone computed tomography (CT) showed thickened skin and membranes medially in the left external auditory canal. Surgical treatment was recommended with no improvement in clinical findings and patient complaints with medical treatment. Onlay tympanoplasty was performed. Postoperative follow-up revealed that the outer ear canal skin was epithelialized normally and the tympanic membrane thickness was normal. In this article, a case of IIMMF is presented with the clinical findings, diagnosis and surgical treatment process in the light of current literature.

Keywords: Idiopathic, Inflammation, Medial Meatal Fibrosis
\end{abstract}

enfeksiyonlar dışında etiyoloji saptanamayan İIMMF olgusu tanısı, medikal ve cerrahi tedavi- si postoperatif izlem süreci güncel literatür eşliğinde sunulmuştur.

\section{Olgu}

65 yaşındaki kadın hasta 15 yıldır sol kulakta sık enfeksiyon geçirme ve işitme azlığı öyküsü ile kliniğimize başvurdu. Yapılan otoskopide dış kulak yolu cildinin mediale doğru kalınlaş- mış lümen çapını azaltmış olduğu izlendi. Timpan zarın mat, kalınlaşmış, başta manibrium mallei olmak üzere landmarkların kaybolduğu ve dış kulak yoluna protrude olduğu görüldü (Resim 1).

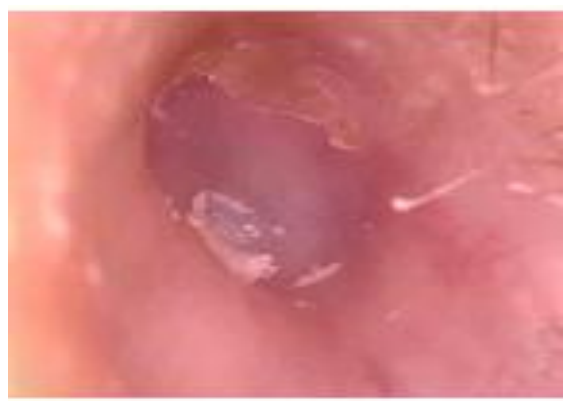

Resim 1. Timpan zar ve dış kulak kanalının preoperatif görüntüsü 
Sağ kulak otoskopisi ve diğer Kulak Burun Boğaz muayeneleri doğaldı. Yapılan saf ses odyometrisinde sol kulakta $500-1000-2000 \mathrm{~Hz}$ de kemik yolu ortalaması $32 \mathrm{~dB}$, hava yolu ortalamas1 50 dB'di. Sağ kulak için 500-1000-2000 Hz de hava ve kemik yolu ortalaması17 dB'di (Resim 2).

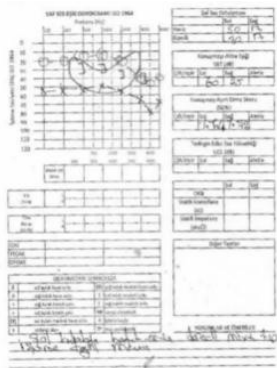

Resim 2. Preoperatif saf ses odyometri

Çekilen temporal kemik BT de dış kulak yolu cildinin mediale doğru kalınlaşmış lümen çapını azaltmış olduğu, sol timpan zarın kalınlaştığı, bilateral orta kulak kemikçikleri ve mastoid hava hücreleri aerasyonunun normal olduğu görüldü (Resim 3)

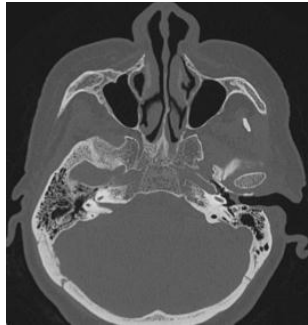

Resim 3. Preoperatif temporal kemik CT

Hasta kortikosteroidli topikal kulak damlası ve sonrasında subkutan depo kortizon uygulaması ile 6 hafta takip edildi. Düzelme izlenmedi. Hasta onay1 ile cerrahi kararı verildi. Genel anestezi altında, mikroskop eşliğinde postaurikular yaklaşım ile inflame ve hipertofik cilt çepeçevre onlay timpanoplasti operasyonundaki teknikle (anulus yaklaşık 8-10 mm lateralinden insizyon ile) tulum şeklinde zar üzeri epitel tabakasıyla birlikte anulus üzerinden siyrilarak eksize edildi. Posteriordan anulus nazikçe kaldırılıp kemikçik zincir eksplore edildi. İnkus ile promon- torium arası ince bridler temizlendi, kemikçik zincir hareketi mikrocerrahi alet tuşesi ile normal olarak izlendi. Temporal kas fasyasından alınan greft onlay olarak serildi, kemik dış kulak yolu eksize edilmiş cilt sahası sekonder epitelizasyona bırakıldı. Dış kulak yolu antibiyotikli gealfoam ile dolduruldu (Resim 4).

Operasyon komplikasyonsuz sonlandırıldı. Patolojiye gönderilen spesmen kronik nonspesifik inflamasyon olarak rapor edildi. Postoperatif 1 . ay kontrolünde dış kulak yolu cildinin normal epitelize olduğu timpan zarın normal kalınlıkta olduğu görüldü (Resim 5). Postoperatif 3. Ay kontrol odyometrisinde sol kulakta $500-1000-2000 \mathrm{~Hz}$ de kemik yolu ortalaması $28 \mathrm{~dB}$, hava yolu ortalaması

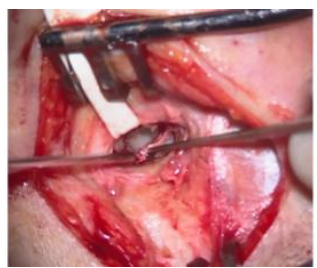

Resim 4. Timpan zarın intraoperatif görüntüsü

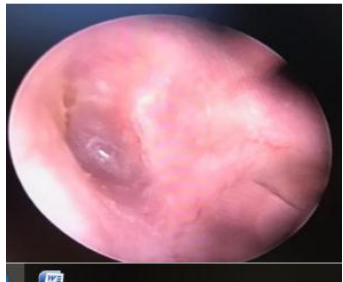

Resim 5. Timpan zarın ve dış kulak yolunun postoperatif 1. ay görüntüsü

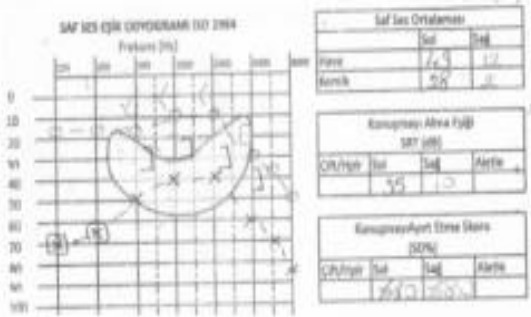

Resim 6. Postoperatif 3. Ay saf ses odyometris

43 dB'di (Resim 6).

\section{Tartışma}

İ̇F etiyolojisinde inflamasyon, travmatik, postoperatif ve neoplastik faktörler suçlansa da en sik postinflamatuar süreçlere bağlı geliştiği görülmüştür (1). İIMMF, vakaların \% 50'sinden fazlasını oluşturan en yaygın tiptir (4). Otitis eksterna, kronik veya rekürren süpüratif otitis media ve diş kulak yolunu etkileyen diğer inflamatuar ve dermatolojik durumların bir komplikasyonu olarak ortaya çıkabilir (5). Literatürde kronik otitis eksternanın birincil ve tek etiyolojik faktör olarak kabul edildiği birkaç olgu da bulunmaktadır (6). Bizim hastamız da tekrarlayan kulak akıntısı ve işitme azlığı şikayetleri ile başvurdu. Rekürren kulak enfeksiyonları dışında etiyoloji bulunamadı.

İIMMF'in patofizyolojisi hala net olarak anlaşılamamıştır, fakat genellikle kabul gören kronik iltihaplanmaların timpan zarın epitel tabakasının kaybına ve sonrasında zarın fibröz tabakası üzerinde olgunlaşmamış granülasyonların birikmesine yol açıp, zamanla bu granülasyon dokularının fibröz dejenerasyona uğramasıdır(7). Kalıcı inflamasyon varlığında, granülasyonların ve fibrozisin daha fazla birikmesi dış kulak yolunun medial kısmını dolduran fibrotik tıkaç oluşumuna yol açar (4). Fibröz tıkaç tüm timpan zarı diffüz olarak örtebilir veya timpan zarın bir bölgesinde lokalize olabilir (8). Bizim hastamızda da dış kulak yolu stenoze ve fibrotik 
dokular ile kaplıydı. Timpan zar kalınlaşmış dış kulak yoluna doğru protrude olmuştu.

Diş kulak yolunun medial meatal cildinde dermis çok incedir, deri ekleri yoktur ve kemiğe doğrudan bağlanır. Ayrıca bu alan, endodermal ve ektodermal epitelyumun doğumdan sonra çok yakın olduğu tek alan olup, patolojik koşullar altında doğrudan temas edip birbirleriyle etkileşime girebilirler (6). Fibrozis ve sonrasında gelişen stenoz dış kulak yolunda kemik kıkırdak birleșimine kadar devam eder, asla kıkırdak bölümü etkilemez (8). Bu hastalarda atrezi medial kemik duvarı yok etmez, bunun yerine medial kanal fibröz tıkaç tarafindan oblitere olur (6).

Kisacası İIMMF, timpan zar üzerinde fibrotik tıkaç birikimi olması sonucu medial dış kulak yolunu oblitere eden ve iletim tipi işitme kaybına yol açan bir süreçtir (4).

$\mathrm{Bu}$ hastalık eğer akılda bulundurulursa tan1 koymak zor değildir. Otoskopide dış kulak yolunun medial duvarı boyunca fibröz dokuların varlığı, saf ses odyometrisinde genellikle orta derecede iletim tipi işitme azlığı ve tekrarlayan kulak enfeksiyonları tanı koydurucu özeliklerdir (1). Temporal kemik BT de orta kulak ve mastoid tutulumu olmaksızın diş kulak yoluna ve timpan zara doğru uzanan fibröz doku görülmesi de tanıyı kolaylaştırır (3). Bizim olgu- muzda yapilan saf ses odyometrisinde sol kulakta 500-1000-2000 Hz de kemik yolu ortalamas1 $32 \mathrm{~dB}$, hava yolu ortalaması $50 \mathrm{~dB}$ 'di. Sağ kulak için 500-1000-2000 Hz de hava ve kemik yolu ortalaması $17 \mathrm{~dB}$ 'di. Temporal kemik CT'de orta kulak ve mastoid doğaldı, sol timpan zar kalınlığı artmış izlenmekteydi.

Histopatolojik incelemede alınan dokuda kronik inflamasyon asekonder hücre infiltratı, kan damarları ve fibröz doku görülür (8). Ek olarak epitel tabakası görülmez (6).

$\mathrm{Bu}$ hastalığın gelişiminde sslak ve kuru evre olmak üzere iki ayrı aşama vardır. Primer yani ıslak evrede epizodik inflamasyon sık görülen otoreye yol açar. Tedavi genellikle düzenli aspirasyon ve antibiyotikli ve steroidli topikal damlaları içerir. Sekonder kuru evrede ise kronik süreç başlamıştır. Biriken granülasyonlar sonucu fibröz tıkaç oluşmuş ve işitme kaybı başlamıştır. Bu aşamada ise cerrahi önerilmektedir (2). Fibrozis başladığında, atrezinin oluşumunun artı önlenemez olduğu düşünülmektedir (9). İIMMF tedavisi bazı özel teknikler gerektirir, çünkü İIMMF tekrarlayabilir (1). Tekrarlayan enfeksiyon ataklarının önlenmesi İİMMF'in erken yönetiminde büyük önem taşır ve hastalığın ilerlemesini yavaşlatabilir; bununla birlikte, cerrahi tedavi, tam kanal obliterasyonu mevcut olduğunda ve işitme kaybı geliştiğinde tek terapötik tedavi seçeneğidir (4).

Literatüre bakıldığında retrospektif ve az sayıda çalışma olmasına rağmen çoğu yazar postoperatif iyi cerrahi sonuçlar bildirmiştir (2). İIMMF'de cerrahi teknik ilk olarak 1966 yılında Paparella ve Kurkjian tarafından tanımlanmıştır. Postaurikular insizyon uygulanmıştır. Bu teknikteki temel adımlar dış kulak yolundaki tüm fibröz dokuları eksize etmek, timpan zarın fibröz tabakasını korumak, dış kulak yolu kemik bölümü genişletmek, kemikçik ve timpan zarı kaplamak için greft alınması, dış kulak yolu açıklığının uzun vadede devam ettirilmesidir (8). Çoğu cerrah operasyonu sonlandırmadan önce diş kulak yoluna en az 2 hafta kalacak şe- kilde antibiyotikli topikal damlalar ile 1slatılmış gelformlar veya ekstrafor şeritler koyulmasını önermiştir (2). Biz de hastamıza onlay timpanoplasti tekniği uyguladık. Dış kulak yoluna 2 hafta kalacak şekilde antibiyotikli gelform ve şeritler yerleştirdik.

Kulakta otore ve aktif enfeksiyon olmas1 durumunda ameliyat ertelenmeli önce topikal kortikosteroid ve antibiyotik damlalarıyla enfeksiyon kontrol altına alınmalı sonra opere edilmelidir (3).

Klinik olarak önemli postoperatif komplikasyonlar persistan otore, timpan zar perforasyonları ve restenoz gelişimidir. Otore ve restenoz en s1k görülen komplikasyonlardır. Literatürde tim- pan zar perforasyonu $\% 1$ ile 8 arasında değişmekte olup, ortalama $\% 4.3$ 'tür (2). Cerrahi sonrası nüks oranı yaklaşık \%10-20 olarak görülmüştür. Nükslerden kaçınmak için dış kulak yolundaki fibröz tıkaç tam olarak çıkarılmadır. Restenozun önlenmesi için fibröz tıkacın tam olarak çıkarılması, dış kulak yolunun yeterince genişletilmesi ve diş kulak yoluna greft yerleştirilmesi önerilmiştir (10). Ayrıca postoperatif enfeksiyonun kontrolü, özellikle İIMMF vakalarında dikkate alınması gereken diğer önemli bir faktördür. (1)

Postoperatif iyi sonuçlar olarak neyin kabul göreceği tartışmalıdır. En sık kabul edilen kriter hava kemik aralığının $20 \mathrm{~dB}$ veya altına inmesidir. Literatürde bu oran $\% 64$ ile 100 arasında sağlanabilmiştir. Cerrahi uygulanacak hastalar iyi seçilmeli ve cerrahi sonrası gelişebilecek komplikasyonlarla ilgili olarak hastalar açık bilgilendirilmelidir (11).

Sonuç olarak, İIMMF nadir görülen ve çoğu zaman atlanan kronik bir kulak hastalığıdır. Hekimler sık tekrarlayan otore, işitme azlığ ve diş kulak yolunun stenoze görüldüğü hastalarda bu tanıyı akıl- da bulundurmalıdır. Dikkatli bir medikal tedavi sonrası fibrotik doku birikimi önlenebilmektedir. Kronikleşmiş süreçte en iyi tedavi seçeneği cerrahidir. Başarılı bir cerrahi sonrası hasta memnuniyeti yüksektir.

Hasta Onamı: Hasta onamı 15.11.2018 tarihinde alınmıştır.

\section{Kaynaklar}

1. Suzukawa K, Karino S, Yamasoba T. Surgical treatment of medial meatal fibrosis. Report of four cases. Auris Nasus Larynx. 2007;34(3):365-8 
2. Ghani A, Smith MC. Postinflammatory medial meatal fibrosis: early and late surgical out- comes. J Laryngol Otol. 2013;127(12):1160-8.

3. Magliulo G, Ronzoni R, Cristofari P. Medial meatal fibrosis: current approach. J Laryngol Otol. 1996;110(5):417-20.

4. Keller RG, Ong AA, Nguyen SA, O'Connell BP, Lambert PR. Postinflammatory medial canal fibrosis: an institutional review and meta analysis of short- and longterm outcomes. Laryngoscope. 2017;127(2):488-95.

5. Magliulo G. Acquired atresia of the external auditory canal: recurrence and longterm re- sults. Ann Otol Rhino Laryngol. 2009;118(5):345-9.

6. Hopsu E, Pitkaranta A. Idiopathic inflammatory medial meatal fibrotizing otitis. Arch Oto- laryngol Head Neck Surg. 2002;128(11):1313-6.
7. Dhooge I, D'Hoop M, Loose D, Acke F. Acquired atresia of the external auditory canal: longterm clinical and audiometric results after surgery. Otol Neurotol. 2014; 35(7):1196-200.

8. Lavy J, Fagan P. Chronic stenosing external otitis postinflammatory acquired atresia: a re- view. Clin Otolaryngol. 2000;25(6):435-9.

9. Hopsu E, Pitkäranta A. Idiopathic inflammatory medial meatal fibrotizing otitis presenting in children. Otol Neurotol. 2008;29(3):350-2.

10. El-Sayed Y. Acquired medial canal fibrosis. J Laryngol Otol. 1998;112(2):145-9.

11. Lin VY, Chee GH, David EA, Chen JM. Medial canal fibrosis: surgical technique, results, and a proposed grading system. Otol Neurotol. 2005;26(5):825-9. 